\title{
28 Research Square \\ MiR-664b-3p Inhibited Triple-Negative Breast Cancer Cell Growth Via Targeting BRIP1
}

\author{
Qiu Jin \\ Jiangsu College of Nursing \\ Bo Lin \\ Jiangsu College of Nursing \\ Wenhui Zhao \\ Jiangsu College of Nursing \\ Runyuan Ji ( $\nabla$ christ777735@163.com ) \\ Jiangsu College of Nursing
}

Research

Keywords: Triple-negative breast cancer, miR-664b-3p, BRIP1

Posted Date: August 17th, 2021

DOI: https://doi.org/10.21203/rs.3.rs-798916/v1

License: (9) This work is licensed under a Creative Commons Attribution 4.0 International License.

Read Full License 


\section{Abstract}

\section{Background}

Many studies indicate that microRNAs (miRNAs) play a crucial role in modulating the development and progression of triple-negative breast cancer (TNBC). However, miR-664b-3p affections on the TNBC functions and mechanisms are still unknown. The purpose of our study was to clarify the effects of miR$664 b-3 p$ in cellular TNBC development and progression.

\section{Methods}

In our study, the expressions of miR-664b-3p in cell lines and tissueswere tested by real-time PCR (RTPCR), immunofluorescence, H\&E and immunohistochemistry staining. CCK-8 assay, colony formation, EdU, flow cytometry apoptosis, wound scratch, Transwell assays were applied to explore the cell functions. The targeted relationship between miR-664b-3p and its target BRIP1 was determined by dualluciferase reporter assay and rescue experiments.

\section{Results}

We observed that miR-664b-3p was significantly decreased in TNBC cell lines. Overexpression of miR664b-3p could observably inhibit cell proliferation, migration, invasion and induced apoptosis in vitro. Meanwhile, miR-664-3p suppressed TNBC tumor growth in vivo. Furthermore, luciferase reporter assays identified the interaction between 3'UTR of BRIP1 and miR-664b-3p. Moreover, we investigated the mechanisms underlying the effect of miR-664b-3p on cell functions, and the result showed that miR664b-3p inhibited cell proliferation, invasion and accelerated apoptosis by targeting BRIP1.

\section{Conclusion}

From the above, our findings indicated that miR-664b-3p played a significant role in TNBC progression by targeting BRIP1, providing new therapeutic targets for diagnostic in TNBC.

\section{Introduction}

Breast cancer is one of the most common cancer in women, and the death rate caused by breast cancer is very high [1, 2], with an estimated annual diagnosis of 1.38 million new cases worldwide [3-6]. The molecular biomarkers were used in routine clinical practice in order to help make treatment decisions for breast cancer that include human epidermal growth factor receptor 2 (HER2), progesterone receptor (PR) and estrogen receptor (ER) [7]. Triple-negative breast cancer (TNBC) does not express any of these receptors, and it is difficult to treat because most chemotherapy only targets one of the three receptors. Furthermore, TNBC accounts for about $20 \%$ of breast cancer and is a highly invasive breast cancer subtype with a higher metastatic rate and lower survival rate than other breast cancer subtypes $[8,9]$. Chemotherapy remains the dominating clinical treatment for early and late TNBC. However, due to the lack of recognized molecular targets, global oncologists face enormous challenges in their fight against 
TNBC [10]. Therefore, it is essential to explore the molecular targets and underlying mechanism of TNBC and provide new biomarkers which can be used for TNBC diagnosis and treatment.

MicroRNAs (miRNAs), a group of small non-coding RNAs, are involved in gene regulation via binding to the 3' non-coding region (3'-UTR) of the target mRNAs [11], leading to mRNA degradation or translational inhibition [12-14]. Many studies indicated that miRNAs were involved in tumor biological processes [15, 16]. There is also increasing evidence that miRNA expression was dysregulated in TNBC and mature miRNAs and played important roles in modulating cell growth, proliferation, differentiation and apoptosis [17-21]. Increasing evidence suggested that miR-664 was down-regulated in several human cancers. For instance, PARP inhibitor increased chemosensitivity by up-regulating miR-664b-5p in BRCA1-mutated triple-negative breast cancer [22]. Li et al. found that miR-664b-5p inhibited hepatocellular cancer cell proliferation through targeting oncogene AKT2 [23]. Moreover, miR-664 promotes cell proliferation via downregulating of FOXO4 in osteosarcoma [24]. However, the contribution of miR-664b-3p downregulation to the development and progression of TNBC remains unknown. Thus, the functional role of miR-664b-3p in TNBC needs further investigation.

In the present study, we investigated the biological functions of proliferation migration, invasion and apoptosis in TNBC cells and identified the target gene. Our study innovatively demonstrated that miR$664 b-3 p$ was a potential biomarker and tumor suppressor in TNBC directly targeting oncogene BRIP1.

\section{Materials And Methods}

\section{Cell lines and cell transfection}

Normal epithelial cells MCF-10A and two human breast cancer cell lines MCF-7, MDA-MB-231 were obtained from the American Type Culture Collection (ATCC). All cells were maintained in RPMI 1640 medium containing $10 \%$ fetal bovine serum (FBS) (Invitrogen) at $37^{\circ} \mathrm{C}$ in a humidified atmosphere with $5 \% \mathrm{CO}_{2}$. miR-664b-3p mimic, mimic NC, miR-664b-3p inhibitor, inhibitor NC, pc-BRIP1 and pc-NC were transfected by using Lipofectamine 2000 (Invitrogen, Shanghai, China) reagent in the light of the manufacturer's instructions.

\section{Rna Extraction And Real-time Pcr Analysis}

RNA from cell lines was extracted using the mirVana miRNA Isolation Kit (Ambion, USA) according to the manufacture's protocol. For validation of miRNA and Real-time PCR assay, TaqMan microRNA Assay protocol (Applied Biosystems) was performed. The internal control was U6 small nuclear RNA and fold change was determined as $2^{-\Delta \Delta C t}$. All tests were performed in triplicate

\section{Western Blot}


Proteins were extracted from cells using RIPA lysis buffer. Proteins were separated by 10\% SDS-PAGE and transferred into PVDF membranes (Millipore Corp., MA). After a block with 5\% milk for $1 \mathrm{~h}$ at room temperature, the membrane was incubated with a primary antibody at $4^{\circ} \mathrm{C}$ overnight. Then, the membranes were incubated with corresponding secondary antibodies for $1 \mathrm{~h}$ at room temperature. The fold change was calculated by normalizing with GAPDH levels.

\section{Cell Proliferation Assay}

Cell proliferation analysis was carried out by using the Cell Counting Kit-8 (CCK-8) and cell colony formation assay. The cells transfected with miR-664b-3p mimics were plated into 96-well plates, and cell proliferation was determined using CCK-8 assay 12 h, $24 \mathrm{~h}$ and 48 h, respectively. The optical density (OD) of the samples was measured with a microplate reader at $450 \mathrm{~nm}$. For the colony formation assay, cells were cultured for $72 \mathrm{~h}$, fixed and stained with crystal violet. Finally, the colonies were photographed and counted under a microscope.

\section{Cell Migration And Invasion Assays}

We used wound healing assay and transwell assay to examine the capacity of cell migration and invasion. For wound healing assay, cells were plated in 6-well plates and allowed to reach 90-95\% confluence. Streaks were created with a $10 \mu \mathrm{l}$ pipette tip. Then, cells were incubated for $24 \mathrm{~h}$ and $48 \mathrm{~h}$. Cells were photographed using microscopy. For transwell assay, MCF-7 and MDA-MB-231 cells were cultured into 6-well plates after transfection for $24 \mathrm{~h}$. Cell migration and invasion activity were detected using a transwell assay. The lower chambers were filled with medium containing $10 \%$ FBS. After the cells were incubated for $24 \mathrm{~h}$ at $37^{\circ} \mathrm{C}$ in $5 \% \mathrm{CO}_{2}$, the non-migrating or non-invading cells were carefully removed with cotton wool. The cells in the bottom chamber were fixed with cold methanol for $10 \mathrm{~min}$, following stained with $0.1 \%$ crystal violet, and then the cells were counted and photographed under a light microscope at a magnification of $200 \times$. All experiments were independently repeated in triplicate independently.

\section{In Vivo Tumor Growth}

All animal procedures were approved by the Animal Care Committee of Jiangsu College of Nursing. BALB/c nude mice were purchased from the Nanjing Biomedical Research Institute of Nanjing University. MCF-7 and MDA-MB-231 cells $\left(1 \times 10^{6}\right)$ stably transfected with miR-664b-3p mimic, mimic NC, miR-664b$3 p$ inhibitor, or inhibitor NC were subcutaneously injected into nude mice. Tumor volume was measured every 3 days and was calculated by the following formula: volume $\left(\mathrm{mm}^{3}\right)=\left(\right.$ length $\times$ width $\left.^{2}\right) / 2$.

\section{Luciferase Reporter Assay}


The full length of the 3'-UTR from BRIP1 containing the target sequence of miR-664b-3p was cloned into the pmiR-RB-report Dual-luciferase miRNA Target Expression Vector (Promega, USA). Then cells were cotransfected with JAK2-WT and JAK2-Mut and miR-664b-3p mimic using Lipofectamine 2000 (Invitrogen). After transfection for $48 \mathrm{~h}$, the luciferase activities were assayed using a Dual-Luciferase Reporter Assay System (Promega). Every experiment was performed in triplicate.

\section{Statistical analysis}

Statistical analysis of the data was performed using SPSS 19.0 software (SPSS Inc., Chicago, IL, USA). Data are expressed as the mean $\pm S D$ of three independent experiments. Differences between the two groups were assessed using a t-test, and multiple groups of comparisons were performed using analysis of variance. $P<0.05$ was considered statistically significant.

\section{Results}

\section{MiR-664b-3p expression is decreased in TNBC cell lines}

To examine the biological relevance of miR-664b-3p, its expression was evaluated in cancer tissues and their corresponding adjacent normal tissues by RT-PCR. Decreased expression of miR-664b-3p was also observed in TNBC cell lines (MDA-MB-231 and MCF-7) compared with normal epithelial cell line MCF-10A (Fig. 1A). These findings indicated that miR-664b-3p might play a putative tumor suppressor role in TNBC.

\section{Mir-664b-3p Regulates Cell Proliferation}

To determine the functional significance of miR-664b-3p in TNBC, we transfected miR-664b-3p mimics, miR-664b-3p inhibitor or blank control into TNBC cell lines MCF-7 and MDA-MB-231. The transfected efficiency and GFP assays were assessed using RT-PCR assay (Fig. 2A). Next, we carried out the CCK-8 analysis to analyze the ability of cell proliferation; the results showed that ectopic expression of miR$664 b-3 p$ significantly decreased cell proliferation as compared to the control group (Fig. 2C). The contrast result was obtained in the miR-664b-3p inhibitor. Mechanically, similar results were obtained in EdU and colony formation assay (Fig. 2D, E). These results indicate an anti-proliferative effect of miR-664b-3p in TNBC.

\section{Mir-664b-3p Mediates Cell Apoptosis}

In order to further explore the influence of miR-664b-3p on TNBC cell apoptosis, the raised percentage of apoptotic cells was measured by flow cytometry in MCF-7 and MDA-MB-231 cells. The results indicated that a significant increase in apoptosis was observed in the cells which transfected with miR-664b-3p mimics and a decrease in the cells that were transfected with miR-664b-3p inhibitor (Fig. 3A). Western 
blot was used to test apoptotic-related factors. As shown in Fig. 3B, we found that restoration of miR$664 \mathrm{~b}-3 p$ significantly suppressed the level of Bcl-2 and increased the levels of Bax, Caspase- 3 and Caspase-9. Therefore, these results indicated that miR-664b-3p induces apoptosis in TNBC cells.

\section{Effect Of Mir-664b-3p On Tnbc Cell Migration And Invasion}

We performed a wound-healing assay with the cells after transfection for $48 \mathrm{~h}$. The results were shown in Fig. 4A. Next, we carried out transwell assays to evaluate the influence of miR-664b-3p on cell migration and invasion. We found that the number of migration and invasion cells was obviously decreased in MCF-7 and MDA-MB-231 cells, which transfected with miR-664b-3p mimics compared with control cells (Fig. 4B). Western blot analysis was used to detect related proteins MMP-2 and MMP-9 (Fig. 4C). These findings mean that ectopic expression of miR-664b-3p inhibits migration and invasion in TNBC cells.

\section{Effect of miR-664b-3p on TNBC tumor growth in vivo.}

Subsequently, the photo of subcutaneous tumors in nude mice was observed (Fig. 5A). The results revealed that the subcutaneous tumors from nude mice in the miR-664b-3p mimic group presented a lower volume and weight compared with those in the mimic NC group (Fig. 5B, C). In addition, HE staining assay and IHC analysis showed that overexpression of miR-664b-3p aggravated cell apoptosis and suppressed the expression level of cell proliferation indicator Ki67 (Fig. 5D). These results strongly suggested that miR-664b-3p mimic restrained TNBC tumor growth in vivo.

\section{Brip1 Is A Target For Mir-664b-3p}

We employed three publicly available miRNA target prediction tools, including records, Targetscan and ncRNA, to predict the targets of miR-664b-3p and searched BRIP1 for further analysis (Fig. 6A). As shown in Fig. 6B, luciferase activity was decreased when the WT BRIP1-3囚UTR and miR-664b-3p mimic were cotransfected compared with the control group. Moreover, the cells which co-transfected with mut BRIP13囚UTR had no effect on luciferase activity. Further, the expression of BRIP1 in cell lines was detected by RT-PCR and western blot. As shown in Fig. $6 \mathrm{C}$ and Fig. 6D, we found that BRIP1 was up-regulated in TNBC cell lines compared with the normal epithelial cell line. In addition, the expression of BRIP1 was measured via RT-PCR and western blot analyses (Fig. 6E, F). These results indicated that BRIP1 is a direct target of miR-664b-3p.

miR-664b-3p inhibits cell proliferation, invasion and accelerates apoptosis by targeting BRIP1

Rescue assays were performed to further study whether miR-664b-3p executed its function in GC by targeting BRIP1. We further investigated the effect of overexpressed-BRIP1 in the presence of miR-664b3p mimic on MCF-7 and MDA-MB-231 cells. The expression of BRIP1 was detected by RT-PCR assay (Fig. 7A). Next, we observed that up-regulation of miR-664b-3p significantly inhibited cell proliferation via CCK-8, EdU assay and colony formation. However, pc-BRIP1 in the presence of miR-664b-3p mimic 
reversed the effect of miR-664b-3p mimic on MCF-7 and MDA-MB-231 cells (Fig. 7B-D). Oppositely, flow cytometry analysis delineated that the promotion of cell apoptosis caused by miR-664b-3p mimic was abolished by pc-BRIP1 (Fig. 7E). Furthermore, the protein expression levels of cleaved-caspase-3, cleavedcaspase- -9 and Bax were increased, and Bcl-2 expression was lessened by transfected with miR-664b-3p mimic and subsequently overexpressed BRIP1 renewed these protein expression levels (Fig. 7F).

Wound healing and transwell chamber assay disclosed that cell migration and invasion suppressed by miR-664b-3p mimic was facilitated on account of BRIP1 overexpressed (Fig. 8A, B). In concert with these results, the effect of miR-664b-3p mimic on the expression levels of MMP2 and MMP9 was recovery by inhibition of BRIP1 (Fig. 8C). These data revealed that miR-664b-3p inhibits cell proliferation, invasion and accelerates apoptosis by targeting BRIP1.

\section{Discussion}

More and more evidence has demonstrated that aberrant expression of miRNAs has been deeply involved in tumor development and progression [25-31]. Increasing evidence has shown that miR-664b-3p acted as a tumor suppressor in various cancers, including pancreatic adenocarcinomas, live cancer and head and neck squamous cell carcinoma [32-35]. However, miR-664b-3p and their biological relevance in TNBC have not yet been determined, and miR-664b-3p was considered as potential specific biomarkers and played an important role in the diagnosis, progression and prognosis of many types of cancers [36].

Here, we researched the potential role of miR-664b-3p in TNBC progression. In the present study, we initially observed miR-664b-3p was significantly down-regulated in TNBC tissues compared with normal tissues, and similar results were shown in cell lines. To further determine the functional biological roles of miR-664b-3p in TNBC cell proliferation, migration, invasion and apoptosis, we ectopically repressed and raised the expression of miR-664b-3p in two TNBC cell lines (MCF-7 and MDA-MB-231). The results showed that ectopic expression of miR-664b-3p resulted in significant inhibition of cell proliferation, migration, invasion as well as promotion apoptosis.

Multiple lines of evidence have proven that microRNAs exert their diverse biological functions, such as acting as key signal transduction mediators in tumor signaling pathways and regulating cell activities, mainly by degrading mRNA or suppressing mRNA translation [37, 38]. BRCA1-interacting C-terminal helicase 1 (BRIP1) was first identified using tandem mass spectrometry by its physical interaction with BRCA1 and also belongs to the Fanconi anemia (FA) genes family. BRIP1 plays a major role in the development of various cancers, including breast cancer $[39,40]$. Moreover, target prediction analysis further confirmed that BRIP1 might be a target of miR-664b-3p. Furthermore, we performed luciferase reporter assays and the data presented demonstrated that BRIP1 represents a direct target gene of miR$664 b-3 p$ in TNBC cells. BRIP1 was overexpressed in TNBC cells. More importantly, further observations illustrated that ectopic miR-664b-3p inhibits cell proliferation, invasion and accelerates apoptosis by targeting BRIP1. 


\section{Conclusions}

In conclusion, our findings indicate that overexpression of miR-664b-3p could inhibit cell proliferation, migration, invasion and induced apoptosis by targeting BRIP1 partially. Generally, our study provides a potential biomarker and miR-664b-3p is expected to become the therapeutic target for the treatment of TNBC. However, the deep-going molecular mechanisms by which miR-664b-3p is involved in the development and progression of TNBC need further investigation.

\section{Declarations}

\section{Acknowledgments}

None.

\section{Conflict of interests}

None.

\section{Authors' contributions}

Qiu Jin and Bo Lin conceived and designed the study. Wenhui Zhao did the main experiments. Bo Lin and Wenhui Zhao analyzed and interpreted the data. Runyuan Ji was responsible for reagents and materials. Qiu Jin and Runyuan Ji drafted the article. Runyuan Ji and Bo Lin revised the article critically. All authors had final approval of the submitted versions.

\section{Funding}

The authors received no funding for this work.

\section{Availability of data and materials}

All raw data were available from the corresponding author on reasonable request.

\section{Ethics approval and consent to participate}

The authors are accountable for all aspects of the work in ensuring that questions related to the accuracy or integrity of any part of the work are appropriately investigated and resolved. This study complied with the Declaration of Helsinki and was approved by the Ethics Committees of the Jiangsu College of Nursing.

\section{Consent for publication}

Not applicable.

\section{Competing interests}


The authors declare that they have no competing interests.

\section{References}

1. SiegelR, Desantis C, Jemal A. Colorectal cancer statistics, 2014.CA Cancer J Clin. 2014;64(2): 104117. doi: $10.3322 /$ caac. 21220 .

2. Matsen, CB, Neumayer LA. Breast cancer: a review for the general surgeon. JAMA Surg. 2013;148(10): 971-979. doi: 10.1001/jamasurg.2013.3393.

3. Loomis D, Huang W, Chen GS. The International Agency for Research on Cancer (IARC) evaluation of the carcinogenicity of outdoor air pollution: focus on China.Chin J Cancer. 2014;33(4):189-196. doi: 10.5732/cjc.014.10028.

4. Rawat A, Gopisetty G, Thangarajan R.E4BP4 is a repressor of epigenetically regulated SOSTDC1 expression in breast cancer cells. Cell Oncol (Dordr). 2014;37(6): 409-419. doi: 10.1007/s13402-0140204-6.

5. Wan SH, Liu YH, Weng YG, et al. BMP9 regulates cross-talk between breast cancer cells and bone marrow-derived mesenchymal stem cells. Cell Oncol (Dordr). 2014;37(5): 363-375. doi: 10.1007/s13402-014-0197-1.

6. Tabarestani $\mathrm{S}$, Ghaderian $\mathrm{SMH}$, Rezvani $\mathrm{H}$, et al.Prognostic and predictive value of copy number alterations in invasive breast cancer as determined by multiplex ligation dependent probe amplification.Cell Oncol (Dordr).2014;37(2):107-118. doi: 10.1007/s13402-013-0165-1.

7. Mulrane L, McGee SF, Gallagher WM, et al. miRNA dysregulation in breast cancer.Cancer Res.2013;73(22): 6554-6562. doi: 10.1158/0008-5472.CAN-13-1841.

8. Joensuu H, Gligorov J. Adjuvant treatments for triple-negative breast cancers. Ann Oncol.2012;6: vi40-vi45. doi: 10.1093/annonc/mds194.

9. Zhao YC. GongZ. WangJ, et al. A randomized phase II study of aromatase inhibitors plus metformin in pre-treated postmenopausal patients with hormon receptor positive metastatic breast cancer.Oncotarget.2017;8(48): 84224-84236. doi: 10.18632/oncotarget.20478.

10. KuoWY, Hwu L, Wu CY, et al. STAT3/NF-kappaB-regulated lentiviral TK/GCV suicide gene therapy for cisplatin-resistant triple-negative breast cancer. Theranostics.2017;7(3): 647-63.doi: $10.7150 /$ thno. 16827.

11. Shukla GC, Singh J, Barik S. MicroRNAs: processing, maturation, target recognition and regulatory functions.Mol Cell Pharmacol.2011;3(3): 83-92. 
12. SalazarC, Nagadia R, Pandit P, et al. A novel saliva-based microRNA biomarker panel to detect head and neck cancers.Cell Oncol (Dordr).2014;37(5): 331-338. doi: 10.1007/s13402-014-0188-2.

13. RaskL, Balslev E, Sokilde R, et al. Differential expression of miR-139, miR-486 and miR-21 in breast cancer patients sub-classified according to lymph node status. Cell Oncol (Dordr). 2014;37: 215-227. doi: 10.1007/s13402-014-0176-6.

14. NagadiaR, Pandit $P$, Coman WB, et al. miRNAs in head and neck cancer revisited.Cell Oncol (Dordr).2013;36(1): 1-7. doi: 10.1007/s13402-012-0122-4.

15. Garcia Al, Buisson M, Bertrand P, et al. Down-regulation of BRCA1 expression by miR-146a and miR146b-5p in triple negative sporadic breast cancers. EMBO Mol Med.2011;3(5): 279-290. doi: 10.1002/emmm.201100136.

16. AlmeidaMI, Reis RM, Calin GA. BRCA1, microRNAs and cancer predisposition: challenging the dogma.Cell Cycle.2011;10(3): 377. doi: 10.4161/cc.10.3.14738.

17. YahyaSM, Elsayed GH. A summary for molecular regulations of miRNAs in breast cancer.Clin Biochem.2015;48(6): 388-396. doi: 10.1016/j.clinbiochem.2014. 12.013.

18. Korner C, Keklikoglou I, Bender C, et al. MicroRNA-31 sensitizes human breast cells to apoptosis by direct targeting of protein kinase $\mathrm{C}$ epsilon (PKCepsilon). J Biol Chem.2013;288(12): 8750-8761. doi: 10.1074/jbc.M112.414128.

19. GaspariniP, Cascione L, Fassan M, et al. microRNA expression profiling identifies a four microRNA signature as a novel diagnostic and prognostic biomarker in triple negative breast cancers. Oncotarget.2014;5(5): 1174-1184. doi: 10.18632/oncotarget.1682.

20. TangW, Yu F, Yao H, et al. miR-27a regulates endothelial differentiation of breast cancer stem like cells.Oncogene.2014;33(20): 2629-2638. doi: 10.1038/onc.2013.214.

21. Mertens-TalcottSU, Chintharlapalli S, Li X, et al. The oncogenic microRNA-27a targets genes that regulate specificity protein transcription factors and the G2-M checkpoint in MDA-MB-231 breast cancer cells. Cancer Res. 2007;67(22): 11001-11011. doi: 10.1158/0008-5472.CAN-07-2416.

22. Song $W$, Tang $L$, $X u$ Y , et al. PARP inhibitor increases chemosensitivity by upregulating miR-664b-5p in BRCA1-mutated triple-negative breast cancer.Sci Rep.2017;7: 42319. doi: 10.1038/srep42319.

23. Li H, Guo D, Zhang Y, et al. miR-664b-5p inhibits hepatocellular cancer cell proliferation through targeting oncogene AKT2. Cancer Biother Radiopharm.2020;35(8): 605-614. doi:

10.1089/cbr.2019.3043.

24. ChenB, Bao Y, Chen $X$, et al. miR-664 promotes osteosarcoma cellproliferation via downregulating of FOXO4. Biomed Pharmacother.2015;75: 1-7. doi: 10.1016/j.biopha.2015.08.012. 
25. Blandino G, Fazi F, Donzelli S, et al. Tumor suppressor microRNAs: a novel non-coding alliance againstcancer.FEBS Lett.2014;588(16): 2639-2652. doi: 10.1016/j.febslet.2014.03.033.

26. XiaopingL, Zhibin $Y$, Wenjuan $L$, et al. CPEB1, a histone-modified hypomethylated gene, is regulated by miR-101 and involved in cell senescence in glioma.Cell Death Dis.2013;4(6): e675. doi: 10.1038/cddis.2013.197.

27. Tessitore A, Cicciarelli G, del Vecchio F, et al. MicroRNAs in the DNA damage/repair network and cancer.Int J Genomics.2014;2014: 820248. doi: 10.1155/2014/820248.

28. Shah NR, Chen H. MicroRNAs in pathogenesis of breast cancer: implications in diagnosis and treatment. World J Clin Oncol.2014;5(2): 48-60. doi: 10.5306/wjco.v5.i2.48.

29. Farazi TA, Hoell Jl, Morozov P, et al. MicroRNAs in human cancer.Adv Exp Med Biol.2013;774: 1-20. doi: 10.1007/978-94-007-5590-1_1.

30. Plank M, Maltby S, Mattes J, et al. Targeting translational control as a novel way to treat inflammatory disease: the emerging role of microRNAs.Clin Exp Allergy.2013;43(9): 981-999. doi: 10.1111/cea.12170.

31. Hsu SD, Tseng YT, Shrestha S, et al. miRTarBase update 2014: an information resource for experimentally validated miRNA-target interactions. Nucleic Acids Res. 2014;42: D78-D85. doi: $10.1093 /$ nar/gkt1266.

32. Ladeiro Y, Couchy G, Balabaud C, et al. MicroRNA profiling in hepatocellular tumors is associated with clinical features and oncogene/tumor suppressor gene mutations. Hepatology.2008;47(6): 19551963. doi: 10.1002/hep.22256.

32. Avissar M, Christensen BC, Kelsey KT, et al. MicroRNA expression ratio is predictive of head and neck squamous cell carcinoma.Clin Cancer Res.2009;15(8): 2850-2855. doi: 10.1158/1078-0432.CCR-083131.

33. BloomstonM, Frankel WL, Petrocca F,et al. MicroRNA expression patterns to differentiate pancreatic adenocarcinoma from normal pancreas and chronic pancreatitis. JAMA.2007;297(17): 1901-1908. doi: 10.1001/jama.297.17.1901.

34. Mathe EA, Nguyen GH, Bowman ED, et al. MicroRNA expression in squamous cell carcinoma and adenocarcinoma of the esophagus: associations with survival.Clin Cancer Res.2009;15(19): 6192200. doi: 10.1158/1078-0432.CCR-09-1467.

35. MicroRNAs and cancer.J Intern Med.2008;263(4): 366-375. doi: 10.1111/j.1365-2796.2008.01926.x.

36. Bracken CP, Scott HS, Goodall GJ. A network-biology perspective of microRNA function and dysfunction in cancer.Nat Rev Genet.2016;17(12): 719-732. doi: 10.1038/nrg.2016.134. 
37. He D, Wang J, Zhang C, et al. Down-regulation of miR-675-5p contributes to tumor progression and development by targeting pro-tumorigenic GPR55 in non-small cell lung cancer.Mol Cancer.2015;14: 73. doi: 10.1186/s12943-015-0342-0.

38. Gupta I, Ouhtit A, Al-Ajmi A, et al. BRIP1 overexpression is correlated with clinical features and survival outcome of luminal breast cancer subtypes. Endocr Connect.2018;7(1): 65-77. doi: 10.1530/EC-17-0173.

39. Rutter JL, Smith AM, Davila MR, et al. Mutational analysis of the BRCA1-interacting genes ZNF350/ZBRK1 and BRIP1/BACH1 among BRCA1 and BRCA2-negative probands from breastovarian cancer families and among early-onset breast cancer cases and reference individuals. Hum Mutat.2003;22(2): 121-128. doi: 10.1002/humu.10238.

\section{Figures}

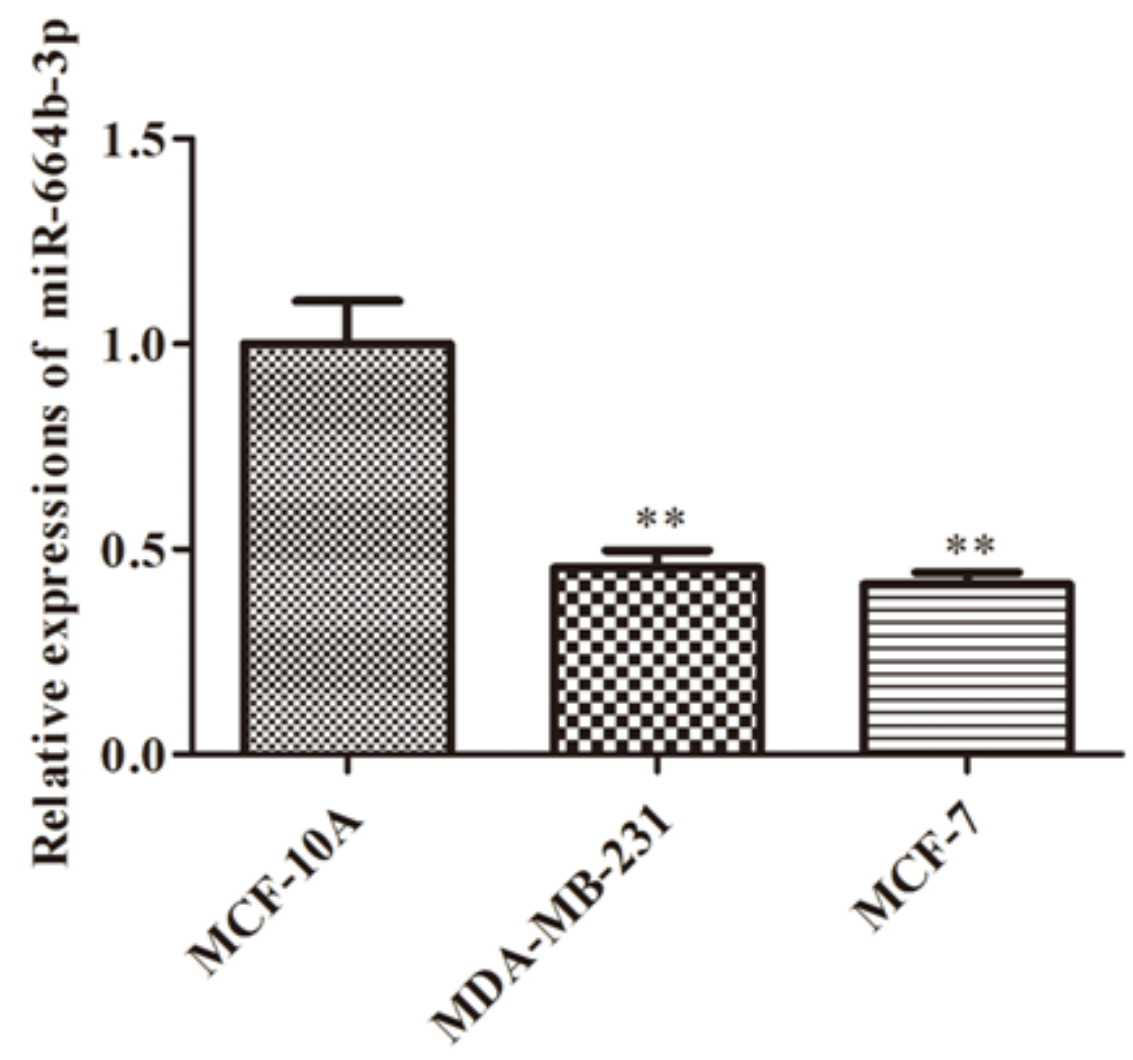

\section{Figure 1}

MiR-664b-3p expression in TNBC cell lines. RT-PCR analysis was analyzed the expression of miR-664b-3p in TNBC cell lines. ${ }^{\star \star} P<0.01$, vs. MCF-10A group. 

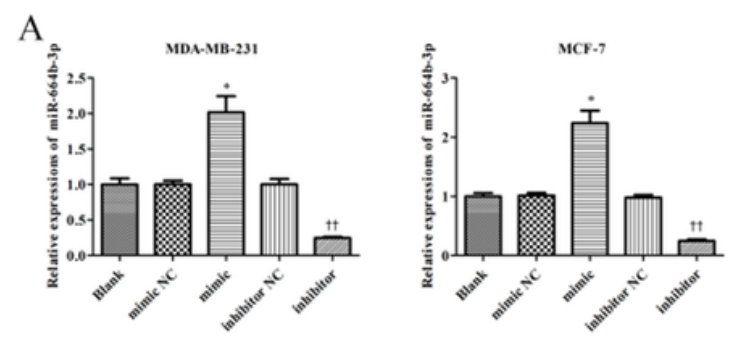

$\mathrm{C}$

MDA-MB-231

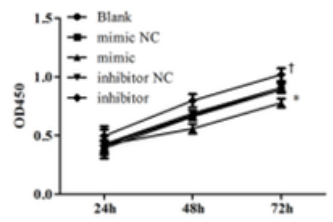

D

D Blank mimic NC

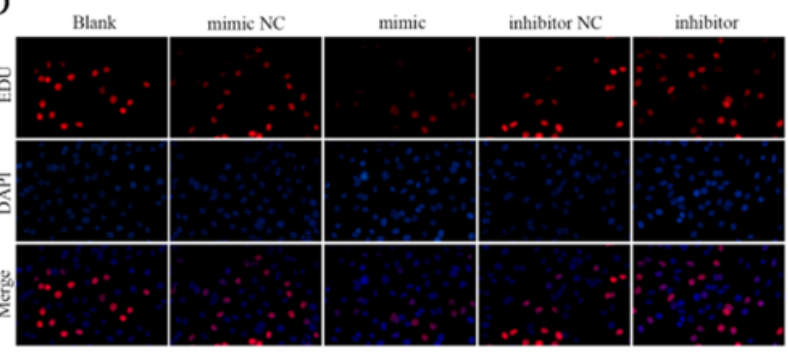

MDA-MB-231

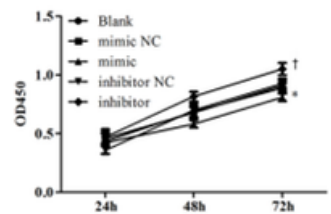

B
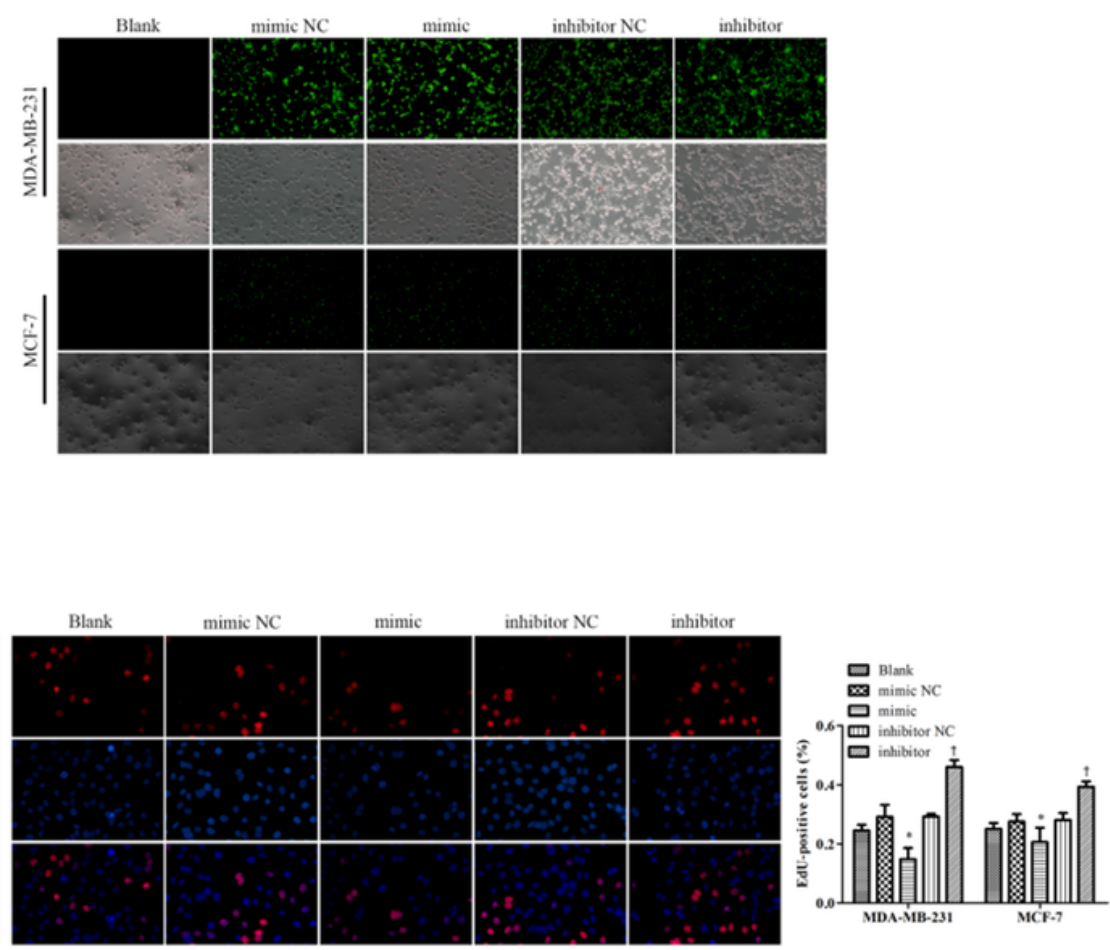
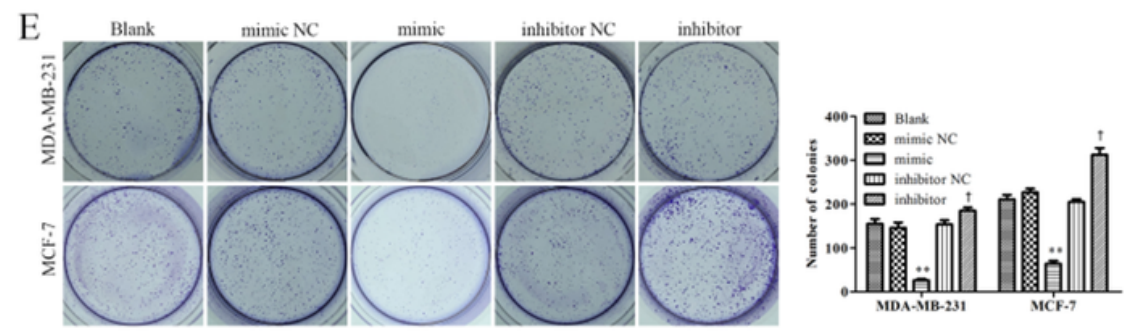

Figure 2

MiR-664b-3p has anti-proliferative effect in TNBC. (A, B) Transfection efficiency was examined by RT-PCR and immunofluorescence. (C-E) CCK-8, EdU and colony formation assay were used to explore the effect of miR-664b-3p in MCF-7 and MDA-MB-231 cell lines. ${ }^{*}<<0.05$, vs. mimic NC group. $\# P<0.05$, \#\#P<0.01, vs. inhibitor NC group. 
A
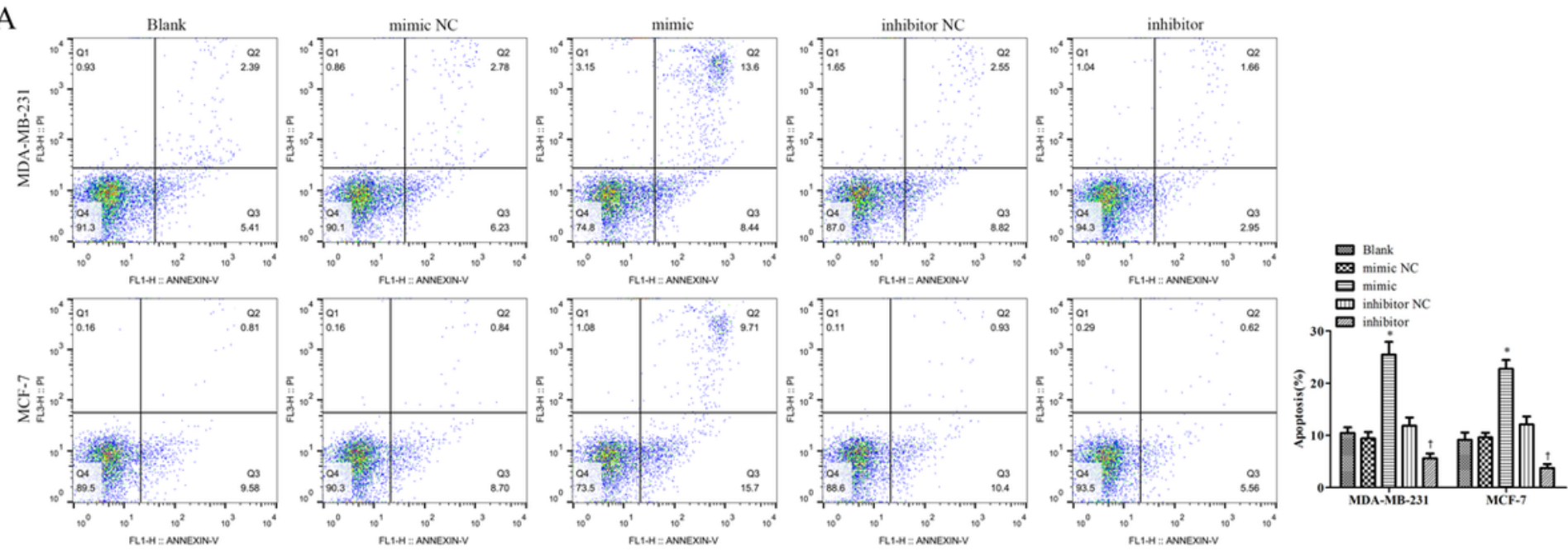

B
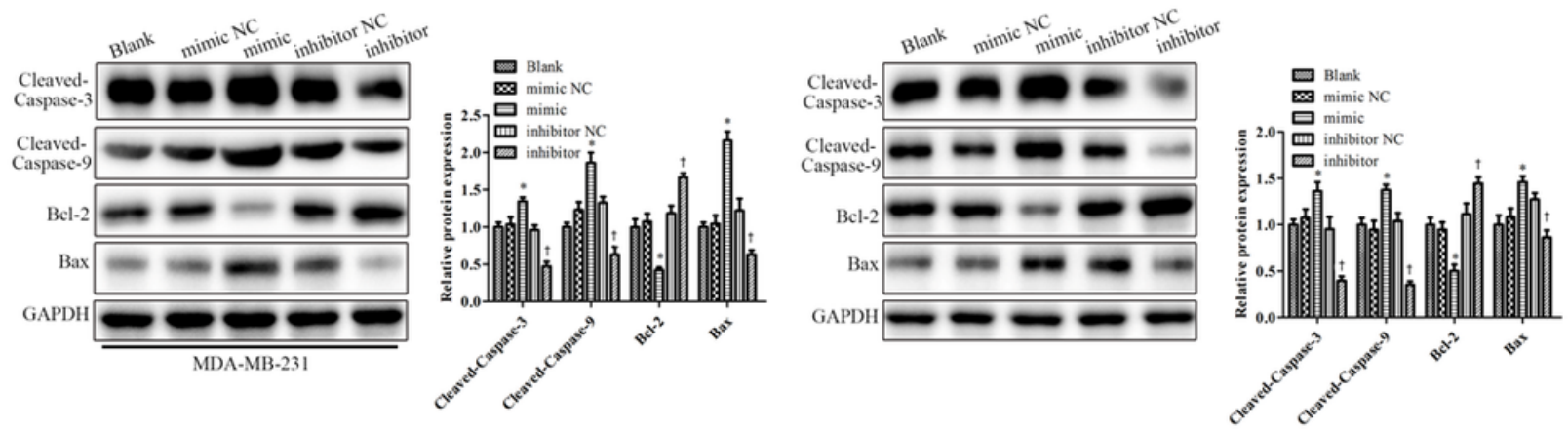

Figure 3

The effect of miR-664b-3p on apoptosis. (A) MCF-7 and MDA-MB-231 cells apoptosis were examined by FCM analysis. (B) Expression of apoptosis-associated markers was detected by western blot. Data are presented as mean \pm SEM of three independent experiments. ${ }^{\star} \mathrm{P}<0.05$, vs. mimic $\mathrm{NC}$ group. $\# \mathrm{P}<0.05$, vs. inhibitor NC group. 
A
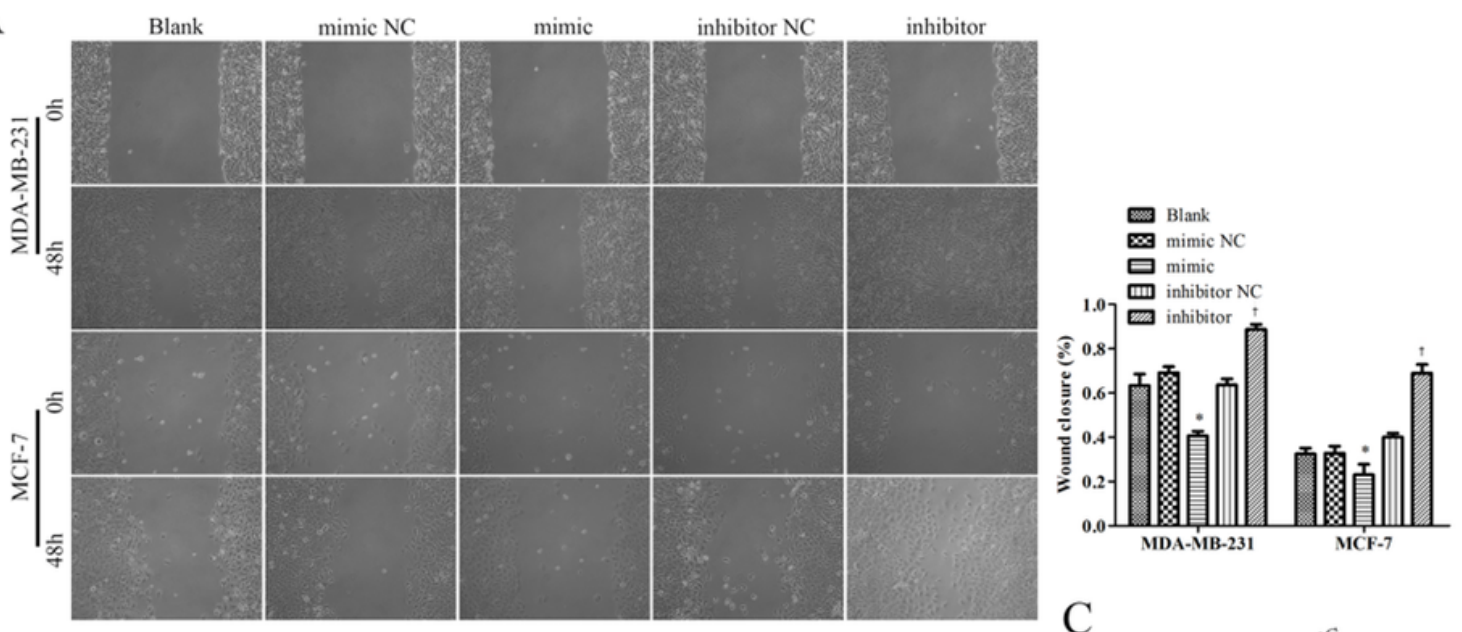

B

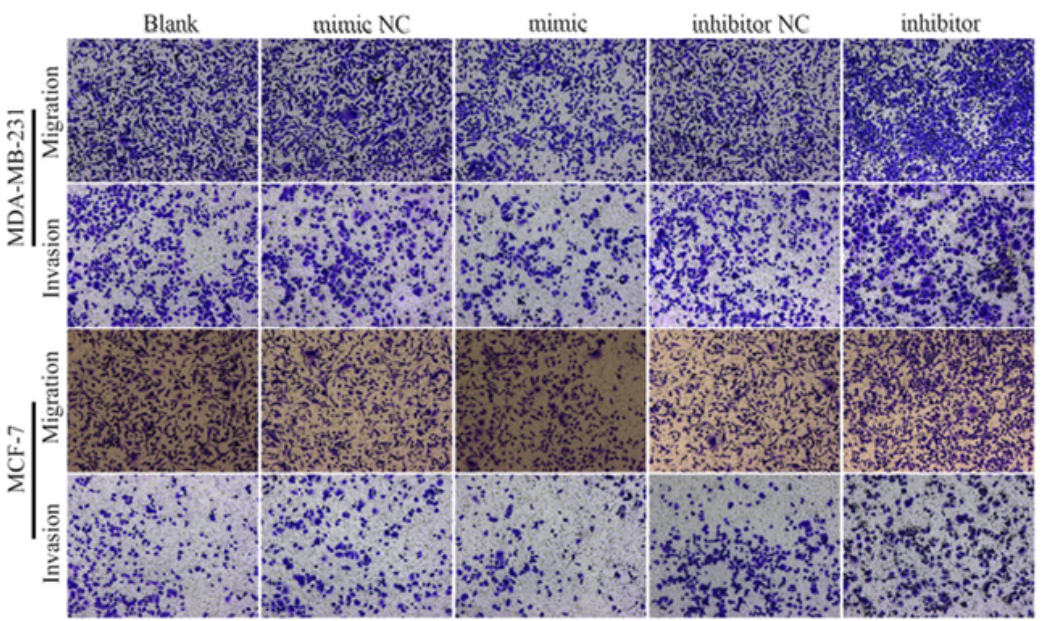

C
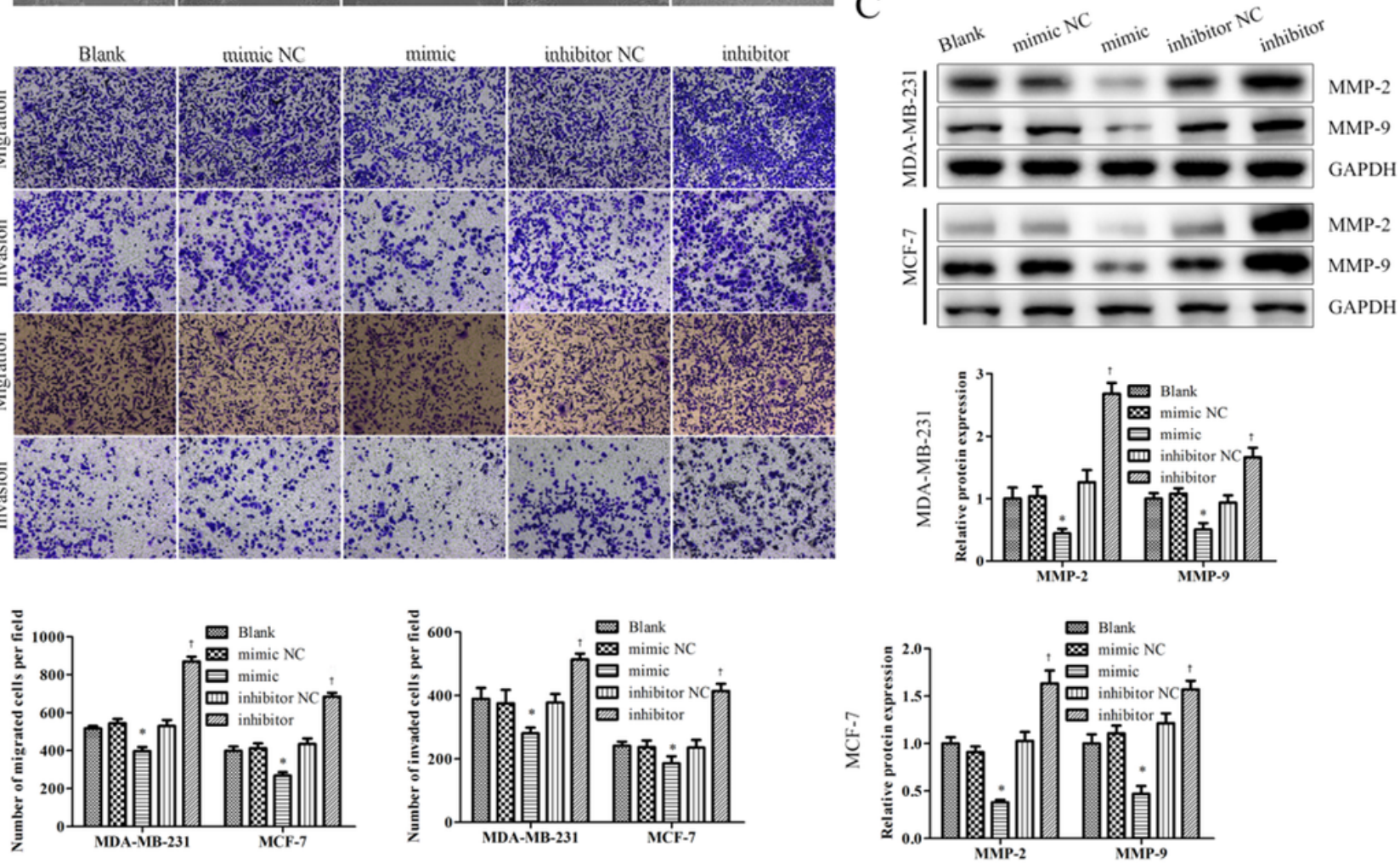

Figure 4

Effect of miR-664b-3p on TNBC cell migration and invasion. (A) Wound healing assays were used to investigate the changes in migration. (B) The number of migratory and invasive cells was determined by transwell assays. Magnification×200. (C) The migration- and invasion-related proteins were detected using western blot.*P<0.05, vs. mimic NC group. \#P<0.05, vs. inhibitor NC group. 
A

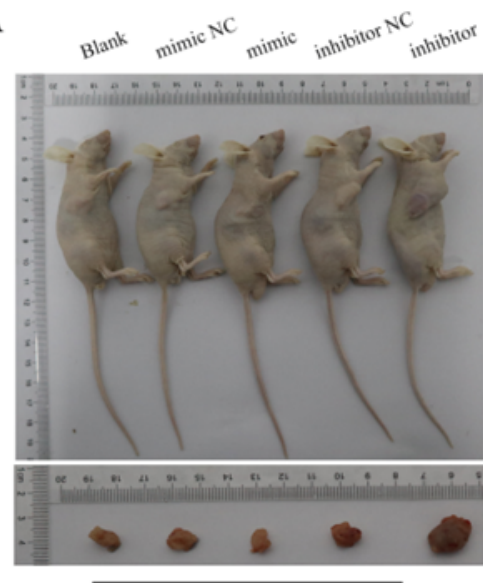

MDA-MB-231

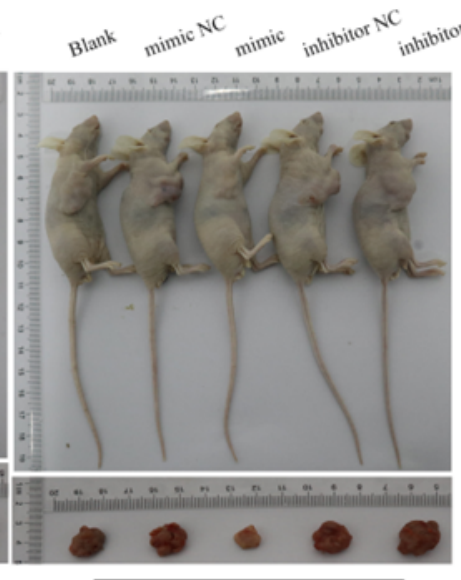

MCF-7

D

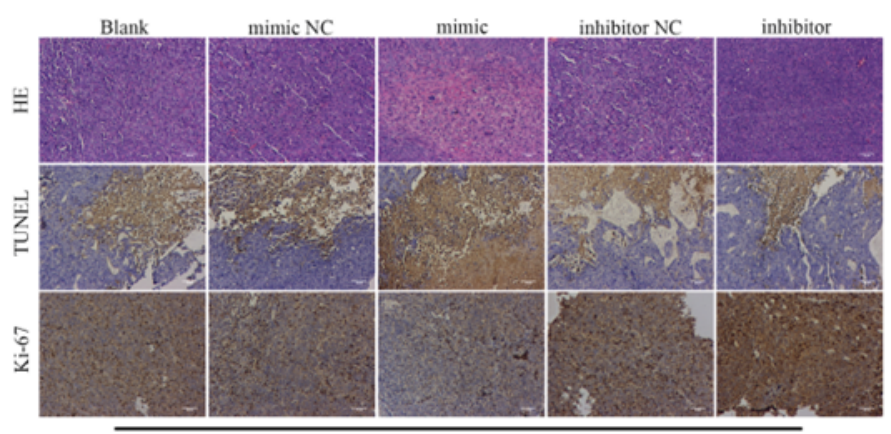

MDA-MB-231

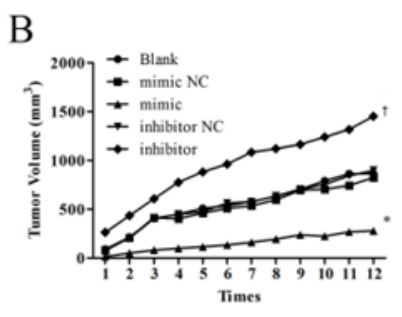

$\mathrm{C}$
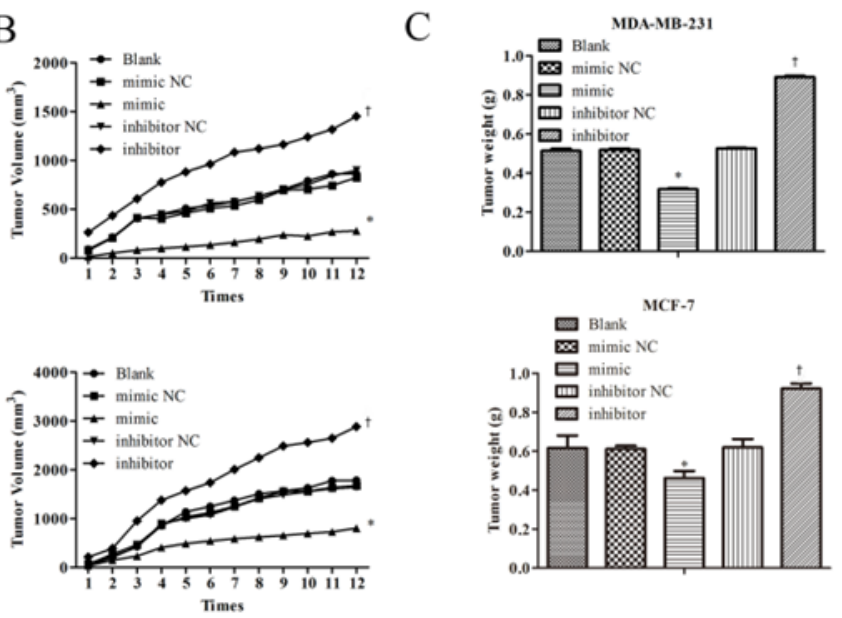

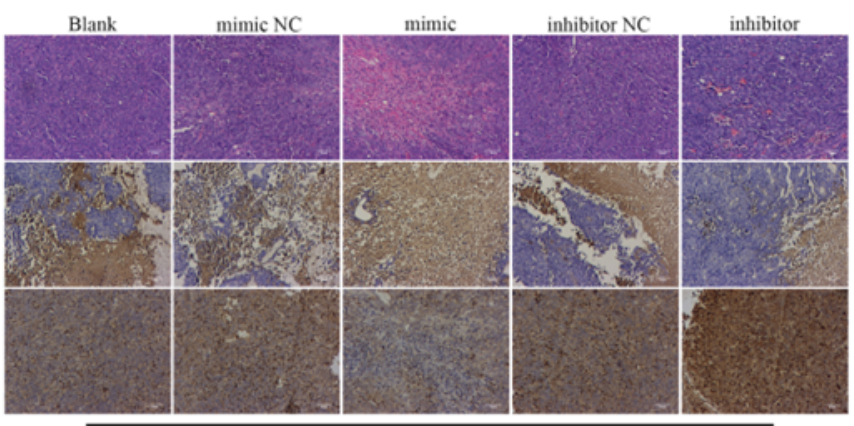

MCF-7

\section{Figure 5}

miR-664b-3p inhibits TNBC tumor growth in vivo. (A) Photographs of tumors from nude mice. (B) Growth curves of xenograft of nude mice were determined based on tumor volume measured every week for 36 days. (C) Tumor weight. (D) HE, TUNEL and Ki67 assays were adopted to analyze the effect of miR-664b$3 p$ on xenograft tumor growth. All experiments were performed in at least triplicate. ${ }^{*} P<0.05$, vs. mimic NC group. \#P<0.05, vs. inhibitor NC group. 
A

$\begin{array}{lc}\text { BRIP1 WT } & 5 \text { '-aacaaCUUGGA---UAAAUGAa-3' } \\ \text { hsa-miR-664b-3p } & 3 \text { '-acauccGACCCUCCGUUUACUu-5 ' } \\ \text { BRIP1 Mut } & 5 \text { '-aacaaGAUCCU----GUUUACUa-3' }\end{array}$

$\mathrm{C}$

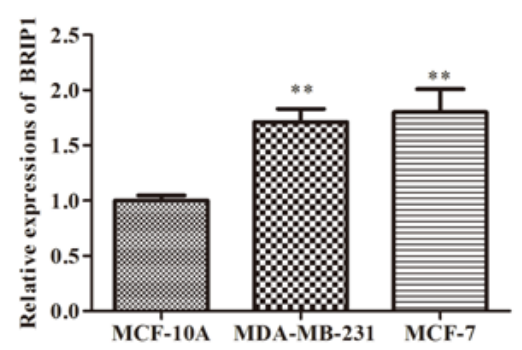

$\mathrm{D}$

$\mathrm{F}$

$\mathrm{E}$

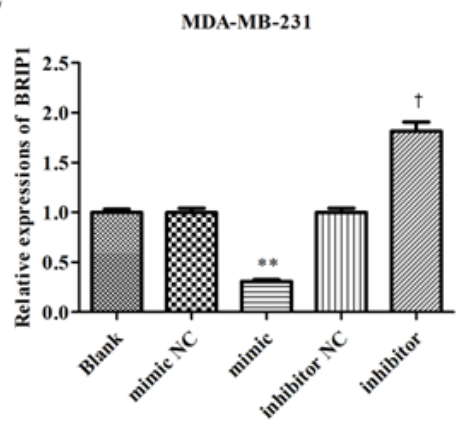

MCF-7

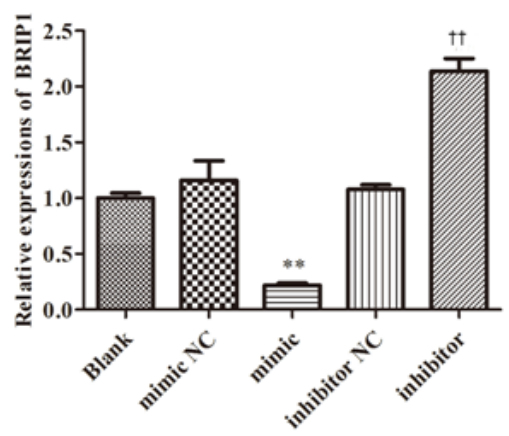

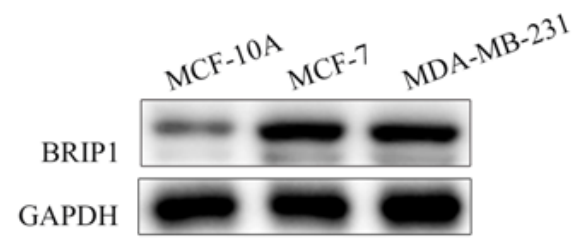

$\mathrm{B}$
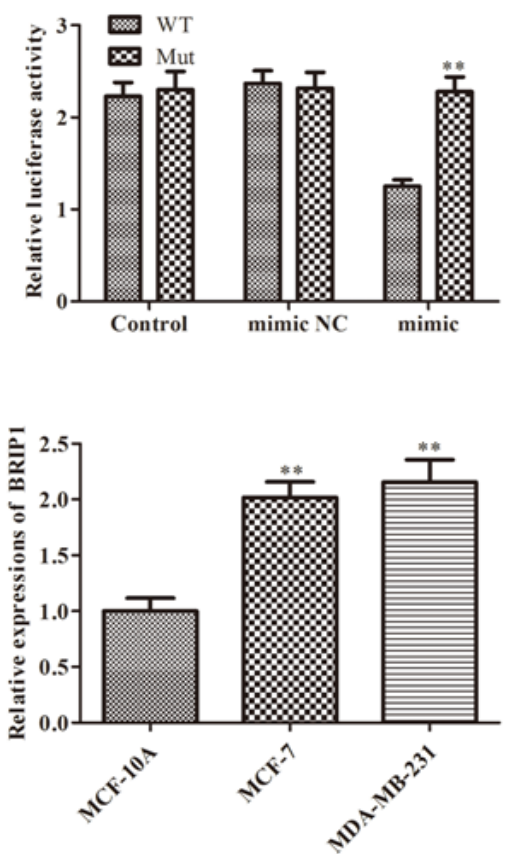

$\mathrm{F}$
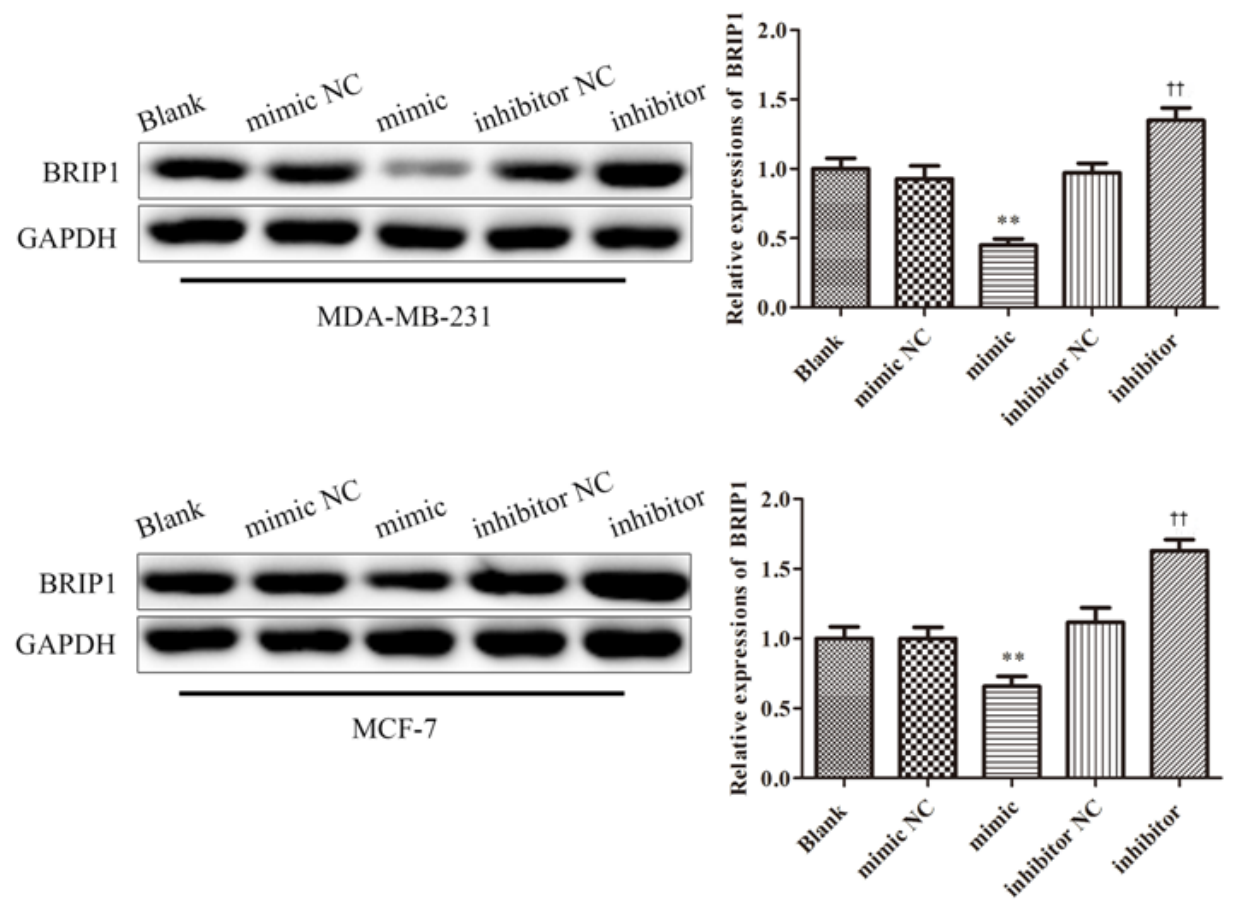

Figure 6

BRIP1 is a target gene of miR-664b-3p. (A) The predicted miR-664b-3p binding site in the BRIP1 3'-UTR.

(B) Relative luciferase activity of cells after co-transfection with wild type (wt) or mutant (mut) BRIP1 3'UTR reporter genes and miR-664b-3p mimic. ${ }^{*} P<0.05$, vs. Mut group. $(C, D) B R I P 1$ protein expressions were detected by RT-PCR and western blot assays in TNBC cell lines. ${ }^{*} P<0.01$, vs. MCF-10A group. (E, F) BRIP1 mRNA and protein expressions were detected by RT-PCR and western blot assays. Data are presented as the means $\pm S D$. ${ }^{\star *} \mathrm{P}<0.01$, vs. mimic NC group. $\# \mathrm{P}<0.05, \# \# \mathrm{P}<0.01$, vs. inhibitor NC group. 
A

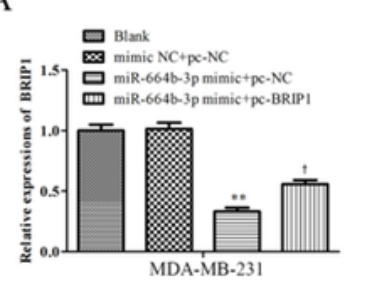

B

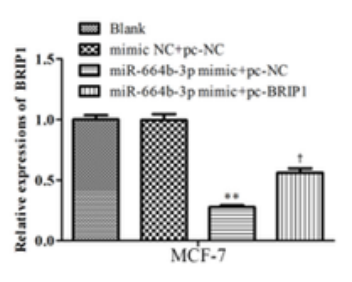

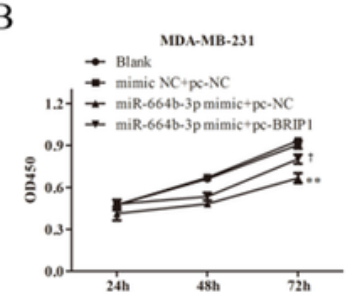
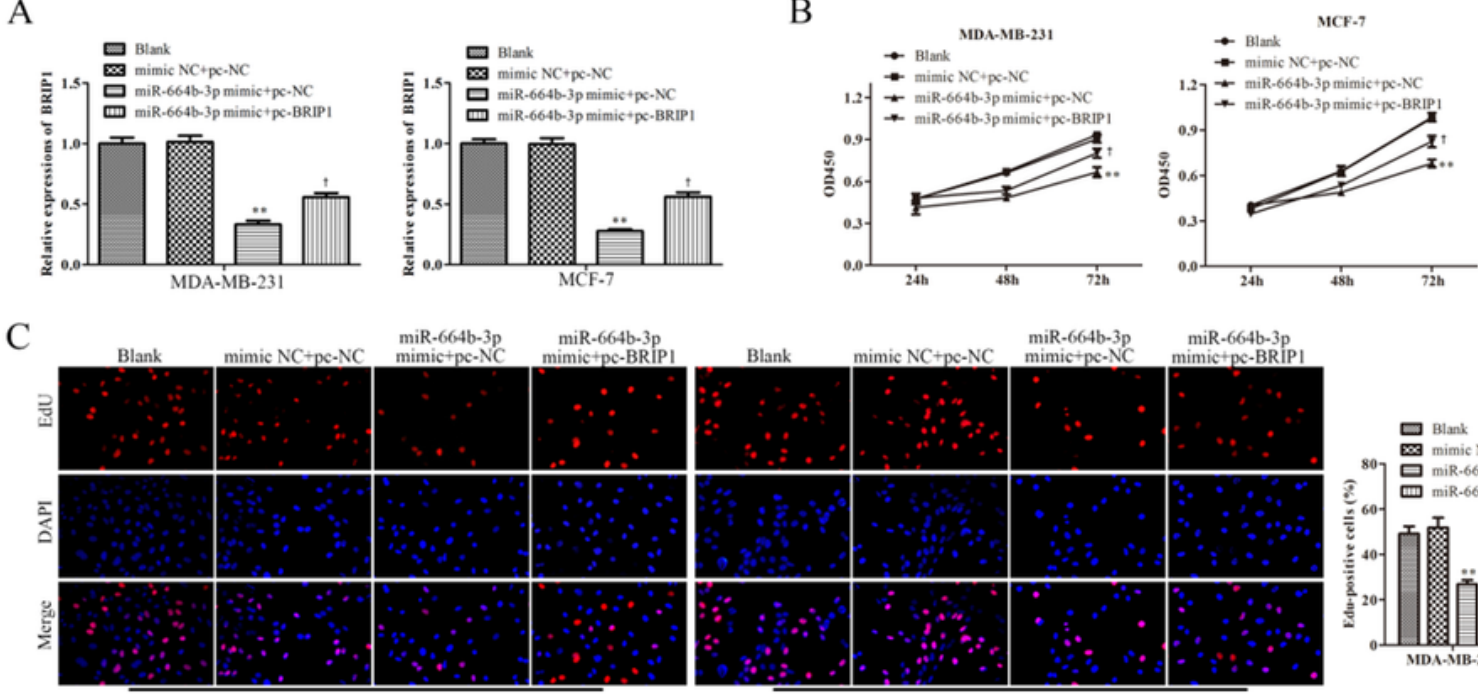

MDA-MB-231
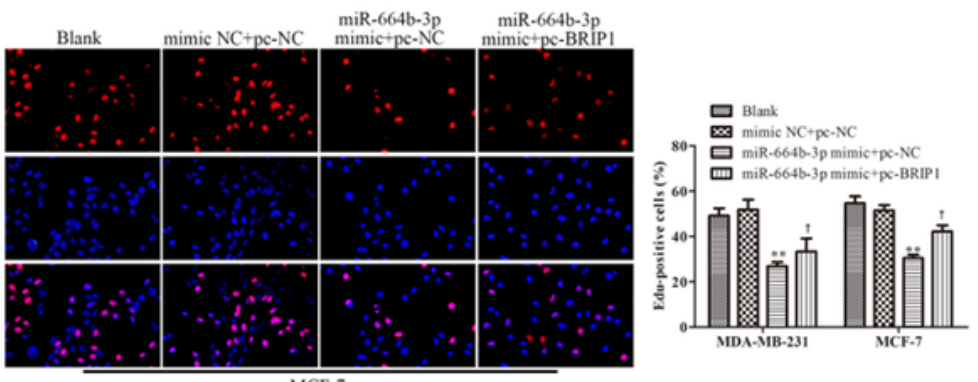

D

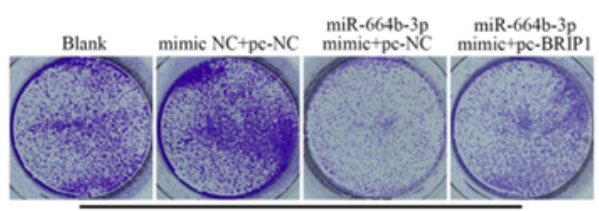

MDA-MB-231
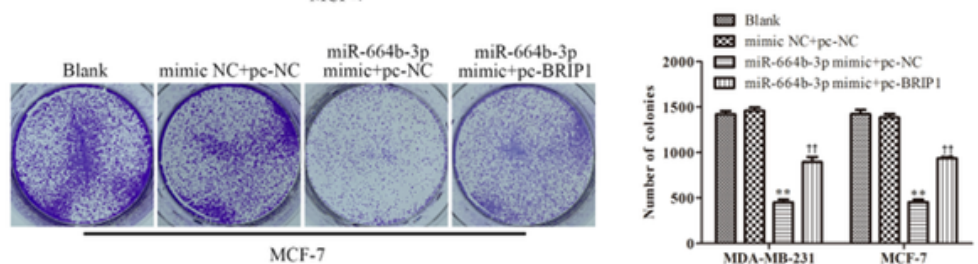

E
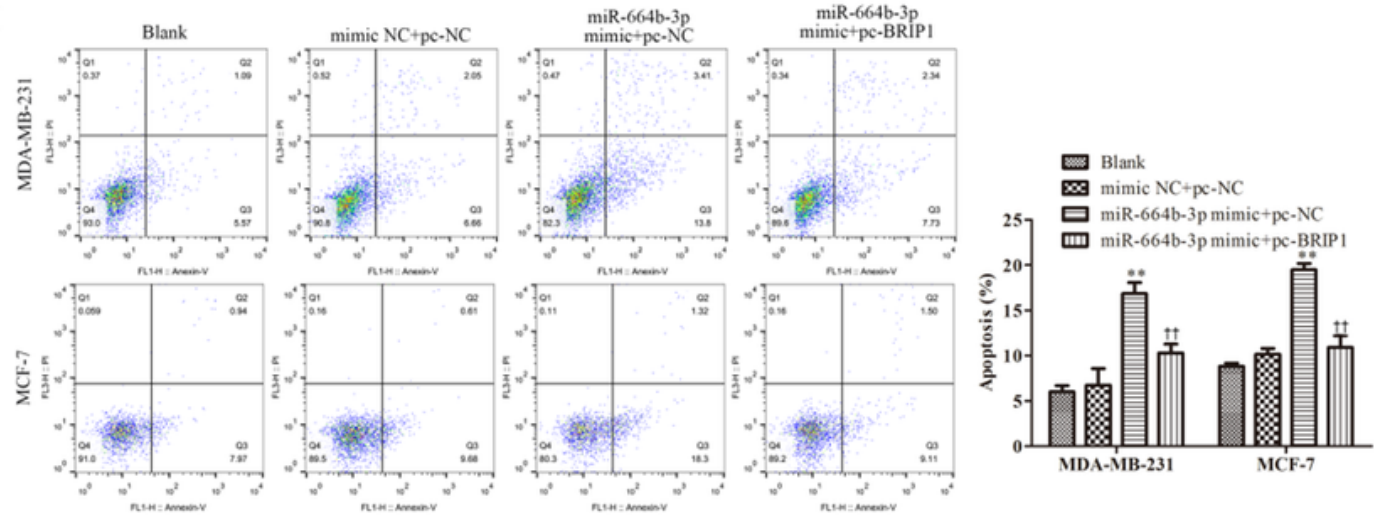

$\mathrm{F}$

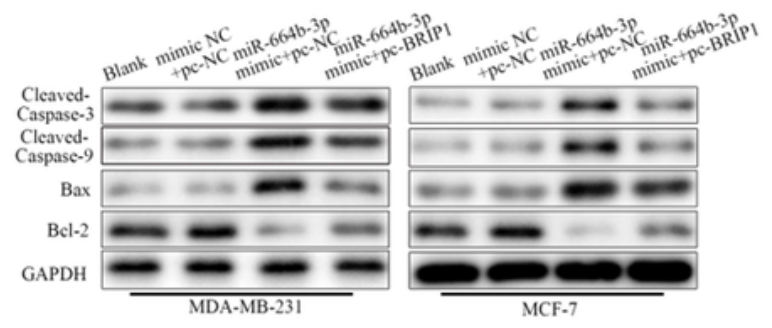

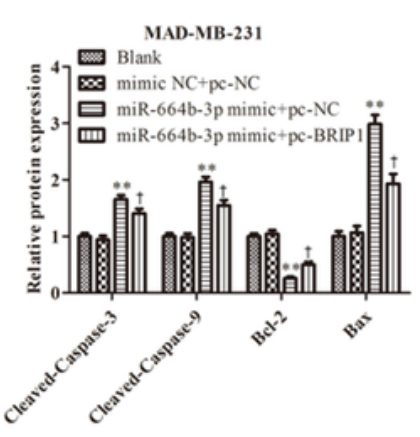

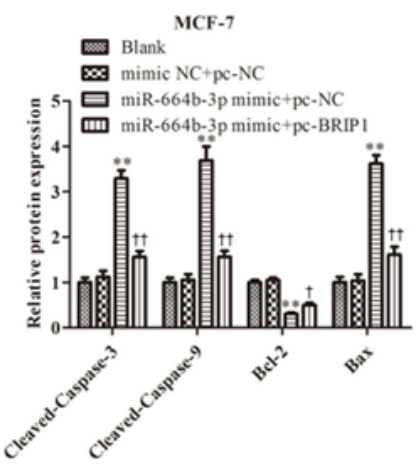

Figure 7

miR-664b-3pinhibitsTNBC cell proliferation and promotes apoptosis by targeting BRIP1. (A) RT-qPCR detection of BRIP1 expression level after transfection. (B-D) CCK-8, EdU and colony formation assays were used to assess the proliferation of TNBC cells. (E) Flow cytometry was used to assess the apoptosis of TNBC cells. (F) Western blot analysis of apoptosis-related protein expression levels. All experiments 
were performed in at least triplicate. ${ }^{\star} \mathrm{P}<0.05$, ${ }^{\star *} \mathrm{P}<0.01 \mathrm{vs}$. mimic $\mathrm{NC}+\mathrm{pc}-\mathrm{NC}$ group. $\# \mathrm{P}<0.05, \# \# \mathrm{P}<0.01$ vs. miR-664b-3p mimics + pc-NC group group.

A

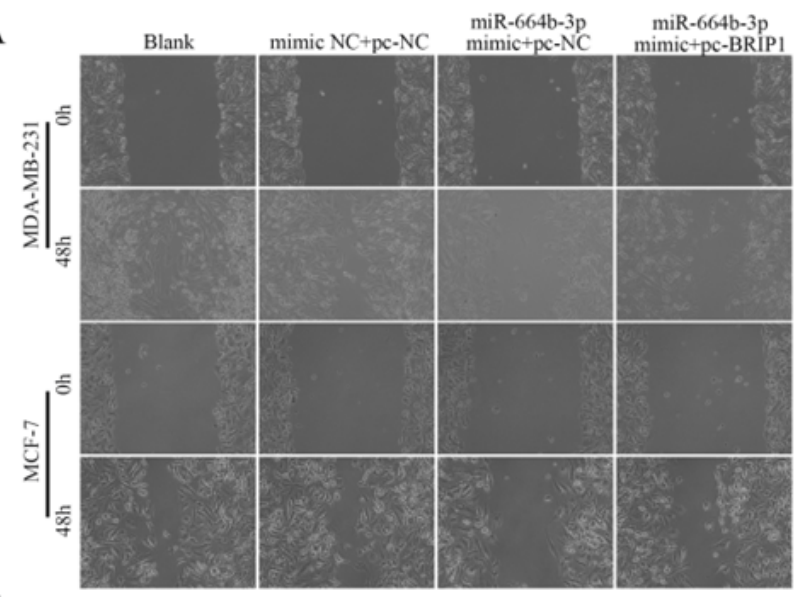

B
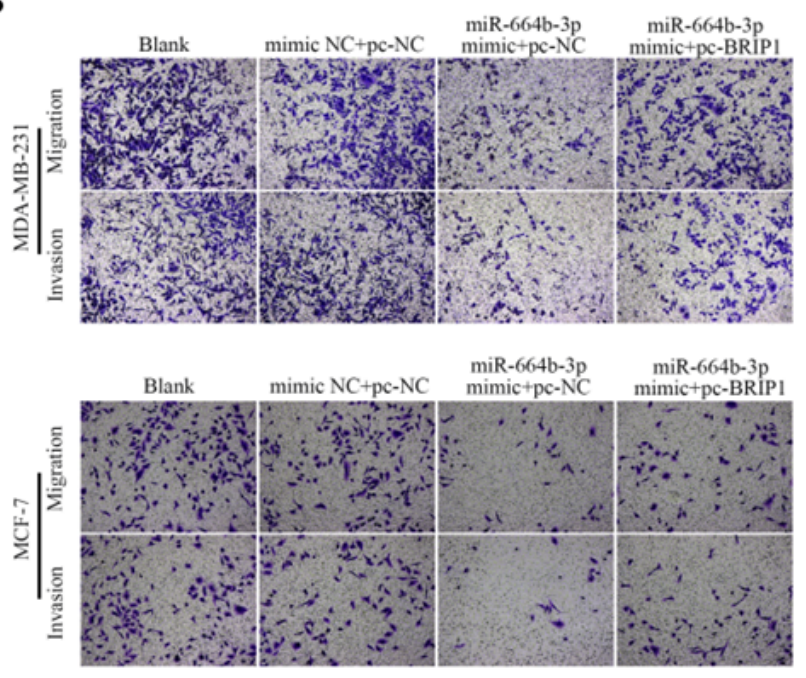
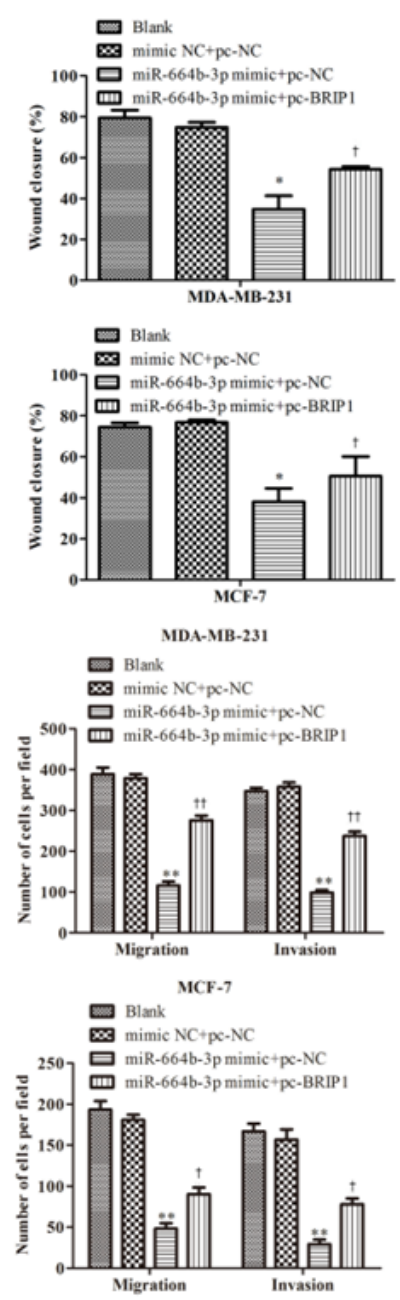

C
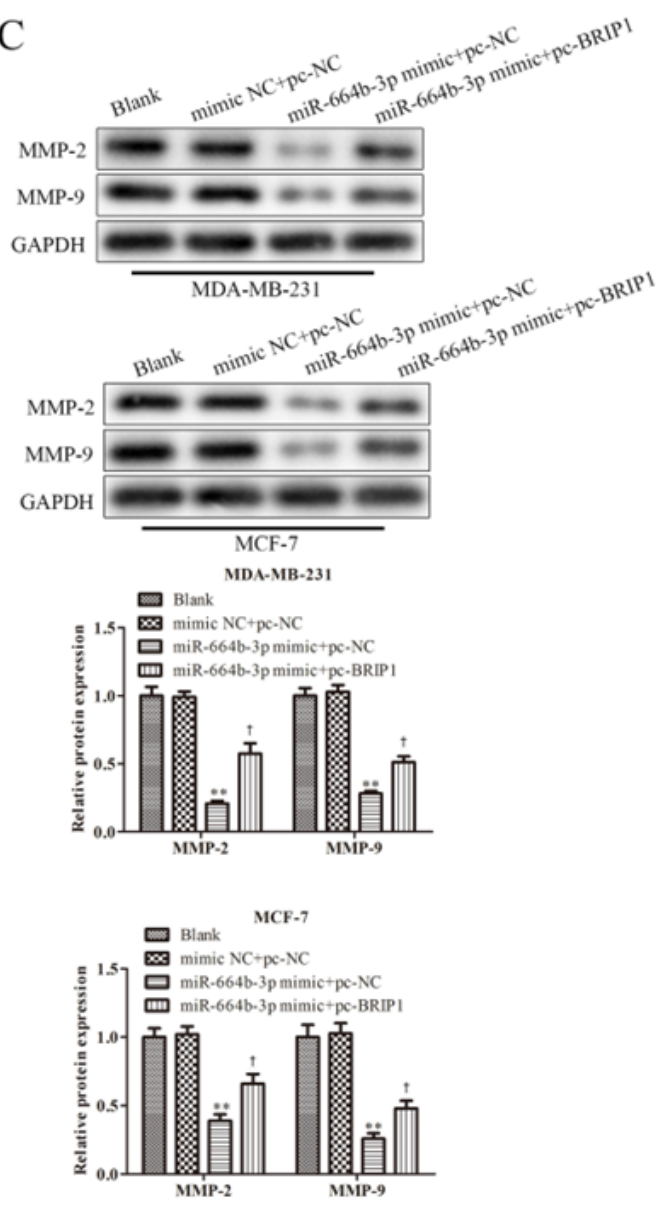

\section{Figure 8}

miR-664b-3pinhibitsTNBC cell migration and invasion by targeting BRIP1. (A, B)Would healingand Transwell chamber assays were used to assess the migration and invasion of TNBC cells. (C) Western blot analysis of MMP2 and MMP9 expression levels. All experiments were performed in at least triplicate. ${ }^{\star} \mathrm{P}<0.05$, ${ }^{\star *} \mathrm{P}<0.01$ vs. mimic NC+ pc-NC group. $\# \mathrm{P}<0.05$, \#\#P<0.01vs. miR-664b-3p mimics + pc-NC group group. 